\title{
Yellow fever vaccine-associated viscerotropic disease: current perspectives
}

\author{
This article was published in the following Dove Press journal: \\ Drug Design, Development and Therapy \\ 12 October 2016 \\ Number of times this article has been viewed
}

\section{Roger E Thomas}

Department of Family Medicine, Faculty of Medicine, University of Calgary, Research Office, G0I2, Health Sciences Centre, Calgary, AB, Canada
Correspondence: Roger E Thomas Department of Family Medicine, Faculty of Medicine, University of Calgary, Research Office, G012, Health Sciences Centre, 3330 Hospital Drive NW, Calgary T2N 4NI, AB, Canada

$\mathrm{Tel}+\mathrm{l} 4032109208$

Fax +l 4032704329

Email rthomas@ucalgary.ca
Purpose: To assess those published cases of yellow fever (YF) vaccine-associated viscerotropic disease that meet the Brighton Collaboration criteria and to assess the safety of YF vaccine with respect to viscerotropic disease.

Literature search: Ten electronic databases were searched with no restriction of date or language and reference lists of retrieved articles.

Methods: All abstracts and titles were independently read by two reviewers and data independently entered by two reviewers.

Results: All serious adverse events that met the Brighton Classification criteria were associated with first YF vaccinations. Sixty-two published cases (35 died) met the Brighton Collaboration viscerotropic criteria, with 32 from the US, six from Brazil, five from Peru, three from Spain, two from the People's Republic of China, one each from Argentina, Australia, Belgium, Ecuador, France, Germany, Ireland, New Zealand, Portugal, and the UK, and four with no country stated. Two cases met both the viscerotropic and YF vaccine-associated neurologic disease criteria. Seventy cases proposed by authors as viscerotropic disease did not meet any Brighton Collaboration viscerotropic level of diagnostic certainty or any YF vaccine-associated viscerotropic disease causality criteria (37 died).

Conclusion: Viscerotropic disease is rare in the published literature and in pharmacovigilance databases. All published cases were from developing countries. Because the symptoms are usually very severe and life threatening, it is unlikely that cases would not come to medical attention (but might not be published). Because viscerotropic disease has a highly predictable pathologic course, it is likely that viscerotropic disease post-YF vaccine occurs in low-income countries with the same incidence as in developing countries. YF vaccine is a very safe vaccine that likely confers lifelong immunity.

Keywords: yellow fever vaccine, viscerotropic disease, postvaccination severe adverse events, systematic review

\section{Introduction \\ Yellow fever (YF)}

YF is caused by a flavivirus endemic in the tropical areas of 31 African and ten Latin American countries (refer to the maps by Monath and Vasconcelos). ${ }^{1}$ The yellow fever virus (YFV) is transmitted in forests and jungles in Africa by Aedes africanus mosquitoes and in South America by Haemagogus and Sabethes species, with monkeys as the primary host and infecting forest dwellers and visitors such as construction workers or loggers. In African savannah areas, Aedes species transmit the virus to monkeys or humans as the intermediate hosts, and in urban areas Aedes aegyptii (which breeds in water containers in or near dwellings) transmits infection between humans (refer to the transmission diagram by Quaresma et al). ${ }^{1,2}$ Because of the greater intensity of urban 
populations, large epidemics are more likely in urban areas. ${ }^{1}$ There has been an intense YFV circulation in Brazil since 1997 and also in Peru, Colombia, Argentina, and Paraguay. In Africa, large epidemics occur in West Africa (irregularly every 5-20 years) and East Africa (at longer intervals such as 45 years), and there have been sustained epidemics in Nigeria, Ghana, and Guinea in the past 30 years. ${ }^{1}$ An outbreak in Angola began in December 2015. Deforestation increases biting by canopy-dwelling vectors at ground level, and colonization of new areas in endemic zones (eg, migration of unvaccinated coastal dwellers into the hinterland in Peru) resulted in an increase in YF cases. ${ }^{1}$ Current risk areas for YF are described in the publications by Jentes et al, ${ }^{3} \mathrm{Hill}^{4}{ }^{4}$ and Rogers et al. ${ }^{5}$ One estimate is that in Africa since 2008 only $1 \%-2 \%$ of the cases suspected on clinical grounds had laboratory proof. Mortality from YF in Africa is $~ 20 \%$ and $40 \%-60 \%$ in Latin America. ${ }^{1}$ The incubation period after a mosquito bite is 3-6 days, and then the patient experiences headaches, fever, muscle and joint aching, poor appetite, and vomiting. Then, there is a 3- to 4-day period of remission with fewer clinical symptoms, and the patient either recovers or goes into the intoxication stage of high fever, abdominal pain, a lowered state of consciousness, and nausea and vomiting. The patient is likely to be jaundiced and have multiple sources of bleeding (hematemesis, melena, petechiae, and ecchymoses) and go into multiorgan failure due to hypotension, fluid loss, capillary fragility, hepatitis, and renal failure. ${ }^{2,6}$ There is rapid viral replication in lymph nodes and then systemic spread to the bone marrow, liver, and spleen. A characteristic pathological sign in the liver is midzonal hepatocellular degeneration with eosinophilic Councilman bodies, and Councilman bodies are also seen in the kidneys and myocardium. ${ }^{6}$ The immune responses involve the proinflammatory cytokine interleukin-6, CD4 ${ }^{+}$ helper lymphocytes, CD8 ${ }^{+}$cytotoxic lymphocytes, and natural killer cells. The main cause of cellular death is apoptosis due to transforming growth factor beta. ${ }^{1,2}$ (refer Figure 5 in Quaresma et $\mathrm{al}^{2}$ ). The seven YFV genotypes (five African and two South American) form a single serotype, and evolutionary rates in all genotypes are similar at $2-5 \times 10^{-4}$ substitutions/ site/year (less than other flaviviruses such as dengue). The South American genotypes I and II differ by up to $16 \%$ at the nucleotide level from the African genotypes, and each subtype contains clades. ${ }^{6}$ Immunity to other flaviviruses confers some immunity to YF. ${ }^{1}$ The signs and symptoms of YF are similar to those of viral hepatitis, malaria, leptospirosis, typhus, Ebola, and other hemorrhagic fevers. An outbreak of YF can go undetected because health workers in remote areas may find it difficult to make a definitive diagnosis based on the signs and symptoms alone, and in mild cases, the patient may be treated at home and not seek health care. ${ }^{7}$

\section{YF vaccines}

Strain 17DD is used to manufacture vaccine in Brazil and 17D-204 by the other five manufacturers, with no significant differences in immunogenicity or safety. ${ }^{1}$ The vaccine replicates initially in lymphoid and reticuloendothelial tissues and is found in the blood in the first week and may persist into the second week. Vaccines based on 17D and using the substrains 17DD and 17D-204 have very low interlot variability and high genetic stability levels. ${ }^{8,9}$ Risk factors for vaccination include thymic disease, a thymectomy, and autoimmune suppression. A review concluded that the evidence for risk for the elderly remains limited, and vaccination should be based on a risk-benefit analysis. ${ }^{10}$

\section{Effectiveness of YF vaccines}

YF vaccination results in an exceptionally strong and lifelong immune response. The log neutralization index to neutralize virus after vaccination averages 2.2 , which is 30 times greater than that needed for protection. The effect is due to a wide-ranging immune response: the production of neutralizing antibodies to highly conserved conformational epitopes in the envelope glycoprotein and to robust $\mathrm{T}$-cell responses $\left(\mathrm{CD}^{+}, \mathrm{CD}^{+}\right.$, and central memory

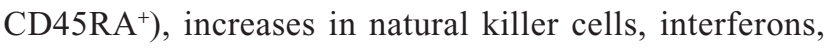
activation of multiple genes by interferons, the complement system, and innate immune sensors (Toll-like receptors), and proinflammatory cytokines (interleukin-6 and -2, tumor necrosis factor, IP-10, MCP-1, and RANTES). ${ }^{1}$ The neutralizing antibodies are found in $90 \%$ of recipients by day 10 (and then the vaccination certificate is valid) and in nearly $100 \%$ by day $30,{ }^{1}$ are thus highly immunogenic $(91 \%-100 \%),{ }^{8,9}$ and provide an estimated $>40$ years of protection. The Global Vaccine Action Plan Alliance (Global Alliance for Vaccines and Immunization) plans to reduce the number of YF deaths from epidemic YF by the planned vaccination of 174 million individuals in Africa and Latin America between 2011 and 2020. From a 1993 Nigerian study, they estimated that one epidemic death would be averted for each 5,000 persons vaccinated. They also estimated that the average interval between epidemics is 17 years, and 4 million persons in the target populations on average would be affected per epidemic with $20 \%$ epidemic incidence and a $20 \%$ proportional case fatality ratio. They assumed 95\% vaccine effectiveness against 
YF death and lifetime immunity and that if population immunity of $>60 \%$ could be achieved, epidemic transmission could be prevented. Based on these assumptions, they computed that vaccinating 174 million individuals between 2011 and 2020 will avert 34,849 deaths in Africa and Latin America. ${ }^{8}$ Travelers from developed countries have shorter exposures and accommodations more protected from mosquitoes, and it is estimated that the risk of disease for an unvaccinated traveler during endemic periods is one in 267 and of death is one in 1,333 in an African country in which YF is endemic, with levels ten times lower in South America. ${ }^{11}$

\section{Serious adverse events after YF vaccination}

The World Health Organization (WHO) defines serious adverse events after YF vaccination as:

An Adverse Event Following Immunization (AEFI) will be considered serious if it results in death, is life-threatening, requires in-patient hospitalization or prolongation of existing hospitalization, results in persistent or significant disability/ incapacity, is a congenital anomaly/birth defect, or required intervention to prevent permanent impairment or damage. ${ }^{12}$

Serious adverse events include anaphylaxis, neurologic, and viscerotropic events. ${ }^{12}$

\section{The Brighton Collaboration case definitions and levels of diagnostic certainty of viscerotropic disease}

The key definition of viscerotropic disease as a serious post-YFV adverse event is the Brighton Collaboration definition (which builds on the initial definition of the US Centers for Disease Control and Prevention working group). The collaboration provides detailed case definitions and diagnostic methods for these serious events reported after YF vaccination: anaphylaxis, neurologic syndromes (encephalitis, myelitis, acute disseminated encephalomyelitis [ADEM], and Guillain-Barré syndrome), and viscerotropic disease (multiorgan failure). The Brighton Collaboration case definitions yield three diagnostic certainty levels: Level 1 (most specific), Level 2, and Level 3 (least specificity and greatest sensitivity). The viscerotopic disease definition provides two classifications: the viscerotropic disease classification is based on seven major and six minor criteria of laboratory evidence of major organ dysfunction and provides three levels of evidence: Level 1 (three major criteria), Level 2 (two major or one major + two or more minor), and Level 3 (jaundice and two or more other minor or three or more minor, or one major and one minor). Viscerotropic disease also provides a second level of classification: an YF vaccine-associated viscerotropic disease (YEL-AVD) classification with suspected, probable, and confirmed levels with the confirmed level based on laboratory confirmation of YF vaccine virus detection. ${ }^{13}$ A patient with post-YF vaccination viscerotropic disease will experience similar symptoms to those of a patient who has wild-type disease. Because many other diseases in YF areas can mimic aspects of viscerotropic disease, the definitions strongly emphasize laboratory confirmation, and clinical symptoms are only assessed as minor criteria. Table 1 lists the major and minor criteria: clinical symptoms and signs occur only as minor criteria for viscerotropic disease and then only as five of seven criteria. The Brighton Collaboration reviewed the clinical symptoms and signs of 36 cases of YEL-AVD and specifically excluded fever, bradycardia, and tachycardia and rated laboratory proof as major criteria (eg, elevated bilirubin) and jaundice as a minor criterion. ${ }^{13}$

\section{Purpose of the review and update}

After five deaths occurred in Peru in 2007 following YF vaccination, ${ }^{14}$ the Global Alliance for Vaccines and Immunization commissioned the WHO to organize a systematic review of the safety of YF vaccine.

\section{Materials and methods Literature search}

For the initial review for the WHO, the Cochrane Library (including the Cochrane CENTRAL Register of Controlled Trials, the Cochrane Database of Systematic Reviews, and the NHS Database of Abstracts of Reviews of Effects), MEDLINE, EMBASE, BIOSIS Previews, Global Health, CAB Abstracts, and the Lilacs Database of Latin American and Caribbean literature were searched for individual studies and systematic reviews through July 10, 2013, with no language or date limits. Reference lists of included articles were searched for additional studies.

\section{Search update}

On May 12, 2016, PubMed and MEDLINE were searched using the terms viscerotropic and (yellow fever vaccine) and (adverse events). Although the original searches were conducted through July 10, 2013, the new search in MEDLINE was conducted in 2011-2016 to avoid missing any publications. 
Table I Major and minor criteria for the case definition of viscerotropic disease

\begin{tabular}{|c|c|}
\hline Major criteria & Laboratory or clinical data \\
\hline Hepatic & Total bilirubin $\geq 1.5 \times$ ULN or $\geq 1.5 \times$ patient's BV or ALT or AST $\geq 3 \times$ ULN or $\geq 3 \times$ patient's BV \\
\hline Renal & Creatinine $\geq 1.5 \times$ ULN or $\geq 1.5 \times$ patient's BV \\
\hline Musculoskeletal & $\mathrm{CPK} \geq 5 \times$ ULN \\
\hline Respiratory & Oxygen saturation $\leq 88 \%$ on room air or requirement for mechanical ventilation \\
\hline Platelet disorder & Platelets $<100,000 / \mu \mathrm{L}$ \\
\hline Hypotension & Requirement for vasopressor drugs to maintain systolic BP \\
\hline Coagulopathy & $\begin{array}{l}\text { INR } \geq 1.5 \text { or prothrombin time } \geq 1.5 \times \text { ULN or activated partial thromboplastin time } \geq 1.5 \times \text { ULN or elevated } \\
\text { fibrin degradation products or hemorrhage from more than one site }\end{array}$ \\
\hline \multicolumn{2}{|l|}{ Minor criteria } \\
\hline Hepatic & Jaundice \\
\hline Renal & Urine output $<500 \mathrm{~mL}$ urine $/ 24$ hours for adults; $<0.5 \mathrm{~mL} / \mathrm{kg} / \mathrm{h}$ for children \\
\hline Musculoskeletal & Positive urine dipstick test for blood with a negative urine microscopy examination for red blood cells \\
\hline Respiratory & Increased respiratory rate for age \\
\hline Platelet disorder & Petechiae or purpura present \\
\hline Hypotension & Systolic BP $<90 \mathrm{mmHg}$ for adults; $<$ fifth percentile for age in children $<16$ years \\
\hline Coagulopathy & $\begin{array}{l}\text { Clinically evident hemorrhage (one of): epistaxis, hematemesis, melena, hematochezia, hemoptysis, } \\
\text { metrorrhagia or menorrhagia, gingival hemorrhage, persistent bleeding from needle puncture sites }\end{array}$ \\
\hline
\end{tabular}

Notes: Symptoms and physical signs are indicated in bold. Adapted from Vaccine, 30(33), Gershman MD, Staples JE, Bentsi-Enchill AD, et al, Viscerotropic disease: case definition and guidelines for collection, analysis, and presentation of immunization safety data, 5038-5058, Copyright 20I2, with permission from Elsevier. ${ }^{13}$

Abbreviations: ULN, upper limit of normal; BV, baseline value; h, hour; BP, blood pressure; ALT, alanine aminotransferase; AST, aspartate aminotransferase; INR, International Normalized Ratio; CPK, creatinine phosphokinase.

\section{Methods}

The data were entered into a specially designed database in Microsoft ACCESS. ${ }^{15}$ For the initial review, all abstracts and full-text articles were independently read by two reviewers (RET, Wendy Spragins) to determine relevance, with any disagreements resolved by a third reviewer (Diane Lorenzetti). To maximize sensitivity in detecting cases, we assessed any report whose title, abstract, or text proposed that a patient had suffered one of the abovementioned serious adverse events after YF vaccination. The systematic review was conducted according to Preferred Reporting Items for Systematic Reviews and Meta-Analyses (PRISMA) ${ }^{16}$ guidelines.

\section{Data collection}

For each case, these data were independently entered by two authors (RET, WS). 1) Age, sex, country, vaccine type, batch number, days till first symptoms, and if the patient died; 2) Brighton Collaboration major and minor criteria and level of diagnostic certainty for each of anaphylaxis, encephalitis, myelitis, acute disseminated meningoencephalitis, GuillainBarré syndrome, viscerotropic disease, and YEL-AVD vaccine-associated causality; 3) laboratory tests for YF and other infectious diseases; 4) other laboratory tests; 5) other findings (past medical history, vaccines, current medications); 6) decisions, with five criteria: i) Is the method by which the authors selected the case clearly described? Did the authors assess probable confounders in the past medical history? Did the authors address probable confounders from medications, vaccines, or other interventions? ii) Are there complete clinical data for the case? iii) Is there complete detection of adverse event following immunization due to YF vaccination with sensitive, specific, and valid outcome measures? iv) Is there complete assessment of probable confounders: other infections, illnesses? v) What is the judgment on this case: does the case meet the Brighton Collaboration criteria and at what level? vi) A Decision Flow Sheet. The principal classification of a case was according to the higher level of evidence reached (eg, if a case met both Encephalitis 2 and ADEM 3 criteria, the principal classification was Encephalitis 2 and the secondary classification ADEM 3). For the update, four new viscerotropic cases discovered by the new literature search were entered. Some cases were published in a series without citation from the original author, and we compared the clinical and laboratory details of all cases to ensure no duplicate cases were included in this systematic review.

\section{Results \\ Literature search}

Electronic and other database searching identified 4,498 abstracts and 66 from other sources, with 2,888 records after removal of duplicates. Of these, 745 articles were selected for full-text retrieval and 93 articles reporting individual cases or series were included in this review (Figure 1). The findings of systematic reviews of pharmacovigilance databases, ${ }^{17}$ active and passive surveillance systems, ${ }^{18}$ and groups regarded at high risk ${ }^{19}$ (children, pregnant females, HIV+ individuals, older persons, patients with malignancy, immunosuppressed or taking immunosuppressive medications) are incorporated into this review. 


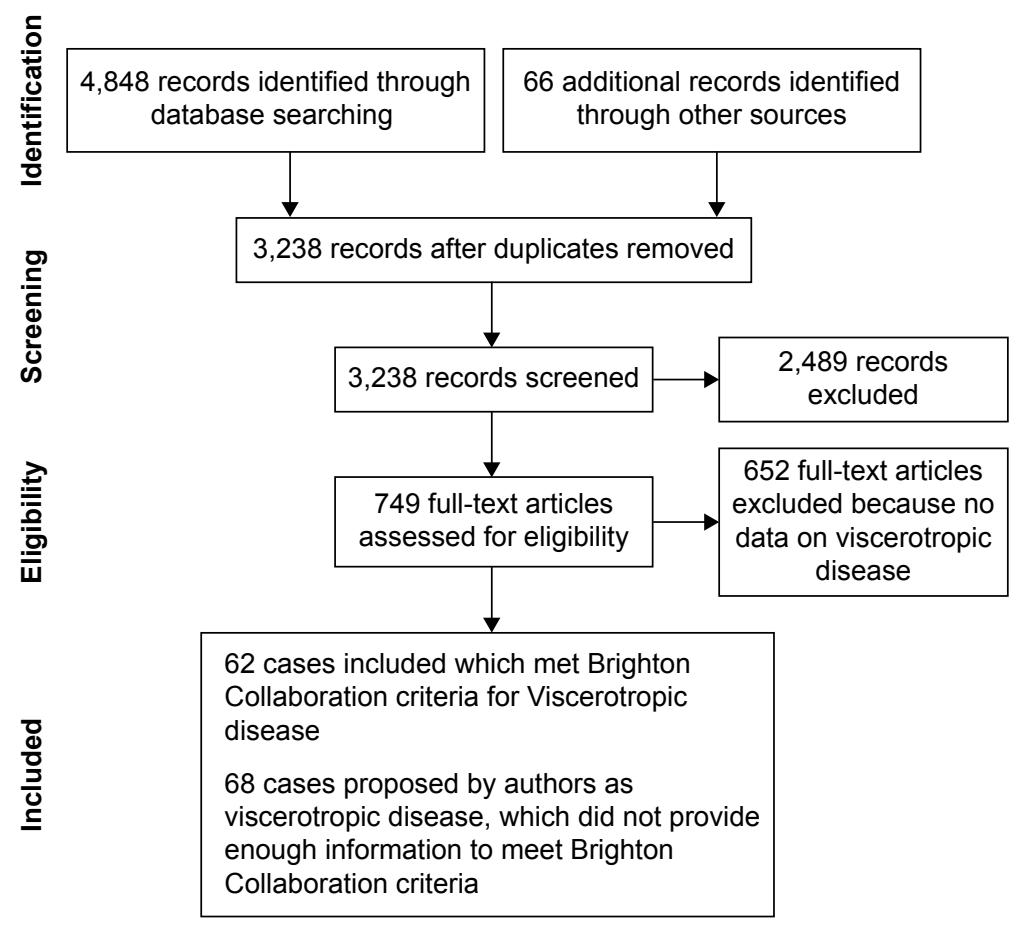

Figure I Preferred Reporting Items for Systematic Reviews and Meta-Analyses (PRISMA) flow diagram.

\section{Search update}

On May 12, 2016, PubMed was searched using the term viscerotropic and 105 citations were retrieved and using the terms (YF vaccine) and (adverse events), 141 citations were retrieved. MEDLINE was searched with same terms, and 67 and 37 citations were retrieved. Four new AVD cases were identified. ${ }^{20-23}$

\section{Cases that met both neurologic and viscerotropic Brighton Collaboration criteria}

One case ${ }^{24}$ met both encephalitis level 1 and viscerotropic level 1 criteria, and the other case, ${ }^{25}$ encephalitis level 2 and viscerotropic level 3 criteria.

\section{Viscerotropic disease: cases that met Brighton Collaboration criteria}

An important result is that all serious adverse events we identified that met Brighton Classification criteria were associated with first YF vaccinations. Sixty-two cases (35 died) met Brighton Collaboration viscerotropic criteria, with 32 from the US, six from Brazil, five from Peru, three from Spain, two from the People's Republic of China, one each from Argentina, Australia, Belgium, Ecuador, France, Germany, Ireland, New Zealand, Portugal, and the UK, and four no country stated. ${ }^{14,20-45}$ Some cases met both viscerotropic and YEL-AVD criteria and some only viscerotropic or YEL-AVD criteria (Table 2). Two cases met both viscerotropic and $\mathrm{YF}$ vaccine-associated neurologic disease criteria. ${ }^{24,25}$ The new search identified four new viscerotropic cases for the database. Case 43 from Biscayart's Argentina report ${ }^{20}$ did not provide enough information to meet any viscerotropic criteria but met YEL-AVD confirmed; the case from Oregon ${ }^{21}$ met viscerotropic level 1 and YEL-AVD confirmed criteria; the case from Hong Kong ${ }^{22}$ met level 2 diagnostic certainty and YEL-AVD confirmed criteria, and the case from New Zealand ${ }^{23}$ met both level 1 certainty and confirmed criteria.

The full data are available in Supplementary materials or from the author. The viscerotropic disease cases are numbers $1-5,23-28,33,42-45,47,49,52,53,56-61,66-69,85,87$, 93-104, 106, 133, 202-212, 217, 227, and 230-233.

\section{Viscerotropic disease: cases that did not meet Brighton Collaboration criteria}

Seventy cases ( 37 died) proposed by authors as viscerotropic disease did not meet Brighton Collaboration criteria (Table 2). There were 26 individual cases ${ }^{41,46-52}$ presented by authors as viscerotropic disease but which provided insufficient evidence to meet either any viscerotropic level of diagnostic certainty or any YEL-AVD causality criteria. In Brazil, a National System for Surveillance of Adverse Events following Immunization was established in 1998, with reports from 30,000 health centers country-wide. Cases were classified 
Table 2 Cases of viscerotropic adverse events that meet and do not meet Brighton Collaboration diagnostic and causality criteria

\begin{tabular}{lllll}
\hline Met Brighton Collaboration Viscerotropic or YEL-AVD criteria or both \\
\hline Viscerotropic level & \multicolumn{2}{l}{ YEL-AVD classification } \\
\cline { 2 - 5 } & Confirmed & Probable & Suspect & Did \\
& 12 & 3 & 5 & 20 \\
\hline Level I & 3 & 1 & - & 6 \\
Level 2 & 2 & - & - & I \\
Level 3 & 1 & - & 8 & - \\
Did not meet any level criteria & I &
\end{tabular}

Did not meet Brighton Collaboration Viscerotropic or YEL-AVD criteria

Cases in individual journal articles

Australia (Lawrence $2003,^{58} 2004^{59}$ )

Brazil: (For overlapping dates):

(I) Martins (2010) ${ }^{56}$ for 1999-2008; reported 26 AVD cases; 21 from Brazil and

5 from other Latin American countries; 19 confirmed, 4 probable, 3 suspect; 24 died;

For none of the Brazilian databases are clinical and laboratory details provided for individual cases (2) Brazilian Ministry of Health for 1999-2008 ${ }^{54-56}$ reported 28 AVD

cases (3) Romano (2014) 57 AVD (2 in the state of Rio Grande do Sul, 3 in the state of Sao Paulo, I in Santa Caterina), all 6 died

USA VAERS: (Khromava; ${ }^{60} \mathrm{n}=7$ AVD with 5 deaths), (Lindsey; ${ }^{61} \mathrm{n}=6$ AVD with

2 deaths)

Total Viscerotropic adverse events (both met and did not meet Brighton criteria)

"serious adverse events" (not further defined, which could include some viscerotropic events: Monath $(2005)^{66}(n=34)$; Schumacher $(2010)^{67}(n=3)$
Total

Did not meet any YEL-AVD criteria

20

6

I

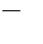

62 (35 died)

$\mathrm{n}=28$ (6 deaths)

$\mathrm{n}=\mathrm{I}$ (no deaths)

$\mathrm{n}=28$ (24 deaths)

$\mathrm{n}=13$ (7 deaths)

132

(72 deaths)

Unknown number of YEL-AVD cases

Notes: To avoid double counting in the different Brazilian reports for the same time, a conservative estimate is 28 cases and 24 deaths. There are three analyses of the US VAERS database with overlapping time periods. Khromava et al for 1990-2002 and Lindsey et al for 2000-2006 divided cases into neurologic or viscerotropic. Martin et al ${ }^{38}$ only presented four cases. However, Martin et al ${ }^{168}$ for the US VAERS database 1990-1998 reported 26 "systemic adverse events (multisystemic or neurologic)" but did not classify them further. His time period overlaps those of Khromava et al and Lindsey et al, and thus, only their analyses are included. Schumacher et al ${ }^{67}$ for the Swiss database reported "seven serious AEFI including four neurologic reactions" (four were assigned to the neurologic total, and the other three undefined cases are recorded as undefined SAEs). The systematic review of studies using active surveillance (Thomas et al' ${ }^{18}$ ) did not find any SAEs. A systematic review of mortality following YF vaccination of troops and civilians during the 1930s and WWII identified an upper limit of 82 military and 24 civilian deaths, but it was difficult to assess the cause of death, and in the troops, it was most likely due to contamination by hepatitis viruses (Thomas et a $\left.\right|^{69}$ ). The summary of the literature (1989-2010) by Monath et a $\left.\right|^{70}$ estimated a world total of I I 3 cases of serious adverse reactions, but clinical and laboratory details of cases are not presented, and it is not possible to cross-check this estimate with the cases in this review. Cases from Monath et al's earlier edition of their chapter are included if sufficient data were presented. Seligman's review reported nine AVD cases already reported in the literature and already included in this review..$^{71}$ Miyaji et al's study of 906 persons 60 years or older who received YFV was able to follow-up 700, and no serious YF AEFls were identified. ${ }^{72}$ Abbreviations: YEL-AVD, yellow fever vaccine-associated viscerotropic disease; US VAERS, US Vaccine Adverse Events Reporting System; AEFI, adverse event following immunization; SAEs, serious adverse events; WWII, World War II; YF, yellow fever; YFV, yellow fever virus.

according to CDC criteria, and a Guideline for Investigation of Serious Adverse Events was developed. There is also a compulsory and immediate reporting system for icterohemorrhagic febrile syndrome for hospitals. ${ }^{53}$ The Brazilian Ministry of Health, ${ }^{54-56}$ Martins et al, ${ }^{53}$ and Romano et al ${ }^{57}$ provide reports for overlapping periods during 2000-2009. The Ministry reports ${ }^{54-56}$ are dated 2009, Martins et al 2010, ${ }^{53}$ and Romano et al 2014, ${ }^{57}$ and (to avoid double counting) the minimum estimate is 28 viscerotropic cases (24 deaths) in Brazil due to AVD. No clinical or laboratory data were provided for individual cases and thus could not be assessed with Brighton Collaboration criteria. An analysis of the Australian databases (Lawrence et $\mathrm{al}^{58,59}$ ) identified one viscerotropic case and the US Vaccine Adverse Events Reporting System (VAERS) database 13 cases (Khromava et $\mathrm{al}^{60}$ seven and
Lindsey et $\mathrm{al}^{61}$ six), which did not provide enough data to meet Brighton Collaboration criteria (Table 2).

\section{Cases proposed by authors as viscerotropic cases but excluded}

Thirty-seven proposed cases from three sources were excluded. The US Vaccine Safety Datalink 1991-2006 ${ }^{62}$ reported International Classification of Diseases (ICD-9) codes for potential adverse events after vaccination. They did not have access to laboratory or imaging studies and could not apply the Brighton criteria. Instead, they applied ICD-9 criteria and created the definition of "visceral" events after YF vaccination and noted one each of cardiac disease, hypotension, and lung disease. The US Department of Defense Database reported adverse events for vaccine-exposed 
military personnel 1999-2007. ${ }^{62}$ There was again no access to laboratory, imaging, or chart data. Thirty-six "visceral" events were identified (not further specified). These cases did not meet Brighton criteria because of the imprecision of the ICD-9 codes in classifying adverse vaccine events, a task for which they were not designed. The "visceral" event classification cannot be related in any way to the Brighton Collaboration, and so these events are not included in this review, except for one death already documented and included in this review. A case from the Netherlands did not meet any Brighton criteria. ${ }^{63}$

\section{Conclusion}

The WHO advises vaccination for all individuals $\geq 9$ months living in countries or areas at risk, except infants 6-8 months or pregnant females or breastfeeding mothers who may be vaccinated during epidemics or if unavoidably traveling to high-risk areas. Similarly, the WHO advises that individuals 60 years and older are at risk for severe adverse events after vaccination, and the risk and benefits need to be weighed. ${ }^{64}$ The US Advisory Committee on Immunization Practices (ACIP) indicates that YF vaccine is contraindicated in those with sensitivity to eggs or chicken, infants $<6$ months, individuals with thymus disorders or who have had a thymectomy, individuals with HIV and AIDS, and individuals on immunosuppressive therapies. The ACIP advises precaution in vaccinating infants aged $6-8$ months, those aged $\geq 60$ years, and individuals with asymptomatic HIV infection and moderate immune suppression (CD4 count 200-499 per $\mathrm{mm}^{3}$ for persons $\geq 6$ years, or $15 \%-24 \%$ of total lymphocytes for children $<6$ years), pregnancy, and breastfeeding. The ACIP notes the limited database for these recommendations. ${ }^{65}$ The published cases of vaccine-associated viscerotropic disease presented here include only developed countries. These cases probably accurately represent the number of cases of viscerotropic disease in these developed countries because patients become so ill they promptly seek care and the initial clinical and laboratory presentations are unusual enough that extensive investigations are likely to be launched. However, an unknown proportion of patients in developing countries with endemic YF are likely exposed to wild-type virus and may not have the same incidence of viscerotropic disease postvaccination as individuals from developed countries. Individuals in developing countries with severe adverse events after vaccination may not reach health care and may not be investigated and published, and thus, the numbers in low-income countries are unknown. The strengths of this review are that the search was conducted from 1930 to July 10, 2013, in multiple databases, with no limitations of language and updated on May 12, 2016. All papers not in English were translated. Titles, abstracts, and full-text articles were assessed independently by two authors. The Brighton Collaboration criteria are specifically designed to assess serious adverse effects after YF vaccination and cases were assessed and data entered independently by two reviewers. The limitations are that only published reports or reports published by manufacturers are included and for many cases insufficient information was provided to assess if they met Brighton criteria. The rates of published viscerotropic disease can be estimated for individual databases. The three analyses of the YEL-AVD cases in the US VAERS database included partly overlapping periods (Khromava et $\mathrm{al}^{60}$ for 1990-2002, Lindsey et $\mathrm{al}^{61}$ for 2000-2006, and Martin et $\mathrm{al}^{38}$ reported only four cases) and provide an estimate of 3.1 per million YEL-AVD and a slightly higher one of 3.9 per million. ${ }^{60,61}$ The Brazilian databases provide a low estimate of 0.19 per million YEL-AVD, ${ }^{53-57}$ and the Australian database of 5 per million. ${ }^{58,59}$ A systematic review that compared active and passive surveillance of post $Y F$ vaccination $(2,660,929)$ reported no YEL-AVD cases. ${ }^{18}$ This review identified 62 cases ( 35 deaths) that met Brighton Collaboration criteria and 70 cases (37 deaths) that did not provide enough information to be assessed with Brighton Collaboration criteria. An overall rate for the current review cannot be computed because the denominators for all the studies are not known. Thus, YF vaccine is a very safe vaccine with a very low rate of YEL-AVD per million, and the findings of this review provide additional support for the abovementioned recommendations of the $\mathrm{WHO}^{64}$ and ACIP. ${ }^{65}$

\section{Disclosure}

The author reports no conflicts of interest in this work.

\section{References}

1. Monath TP, Vasconcelos PF. Yellow fever. J Clin Virol. 2015;64: $160-173$.

2. Quaresma JAS, Pagliari C, Medeiros DBA, Duarte MIS, Vasconcelos PFC. Immunity and immune response, pathology and pathologic changes: progress and challenges in the immunopathology of yellow fever. Rev Med Virol. 2013;23(5):305-318.

3. Jentes ES, Poumerol G, Gershman MD, et al; Informal WHO Working Group on Geographic Risk for Yellow Fever. The revised global yellow fever risk map and recommendations for vaccination, 2010: consensus of the Informal WHO Working Group on Geographic Risk for Yellow Fever. Lancet Infect Dis. 2011;11(8):622-632.

4. Hill DR. Mapping the risk of yellow fever infection. Curr Infect Dis Rep. 2012;14(3):246-255.

5. Rogers DJ, Wilson AJ, Hay SI, Graham AJ. The global distribution of yellow fever and dengue. Adv Parasitol. 2006;62:181-220.

6. Beasley DW, McAuley AJ, Bente DA. Yellow fever virus: genetic and phenotypic diversity and implications for detection, prevention and therapy. Antiviral Res. 2015;115:48-70. 
7. WHO Emerging and Other Communicable Diseases, 1998. District Guidelines for Yellow Fever Surveillance. Geneva: World Health Organization; 1998. [Report No: WHO/EPI/GEN/98.09].

8. Barrett AD, Monath TP, Barban V, Niedrig M, Teuwen DE. 17D yellow fever vaccines: new insights. A report of a workshop held during the World Congress on medicine and health in the tropics, Marseille, France, Monday September12, 2005. Vaccine. 2007;25(15):2758-2765.

9. Pugachev KV, Guirakhoo F, Ocran SW, et al. High fidelity of yellow fever virus RNA polymerase. J Virol. 2004;78(2):1032-1038.

10. Rafferty E, Duclos P, Yactayo S, Schuster M. Risk of yellow-fever vaccine-associated viscerotropic disease among the elderly: a systematic review. Vaccine. 2013;31:5798-5805.

11. Lee LA, Franzel L, Atwell J, et al. The estimated mortality impact of vaccinations forecast to be administered during 2011-2020 in 73 countries supported by the GAVI Alliance. Vaccine. 2013;31(suppl 2):B61-B72.

12. World Health Organization Regional Office for the Western Pacific Region. Immunization Safety Surveillance: Guidelines for Immunization Programme Managers on Surveillance of Adverse Events Following Immunization. 2nd ed. Manila, Philippines: WHO Press; 2013.

13. Gershman MD, Staples JE, Bentsi-Enchill AD, et al. Viscerotropic disease: case definition and guidelines for collection, analysis, and presentation of immunization safety data. Vaccine. 2012;30(33):5038-5058.

14. Whittembury A, Ramirez G, Hernández H, et al. Viscerotropic disease following yellow fever vaccination in Peru. Vaccine. 2009;27(43): 5974-5981.

15. Thomas RE, Jackson D. A database in ACCESS for assessing vaccne serious events. Vaccine. 2015;5:9-16.

16. Moher D, Liberati A, Tetzlaff J, Altman DG; The PRISMA Group. Preferred reporting items for systematic reviews and meta-analyses: the PRISMA statement. PLoS Med. 2009;6(6):e1000097.

17. Thomas RE, Lorenzetti DL, Spragins W, Jackson D, Tyler Williamson T. Reporting rates of yellow fever vaccine 17D or 17DD-associated serious adverse events in pharmacovigilance data bases: systematic review. Curr Drug Saf. 2011;6(3):145-154.

18. Thomas RE, Lorenzetti DL, Spragins W, Jackson D, Williamson T. Active and passive surveillance of yellow fever vaccine 17D or 17DDassociated serious adverse events: systematic review. Vaccine. 2011; 29(28):4544-4555.

19. Thomas RE, Lorenzetti DL, Spragins W, Jackson D, Williamson T. The safety of yellow fever vaccine 17D or 17DD in children, pregnant women, HIV+ individuals, and older persons: systematic review. J Trop Med Hyg. 2012;86(2):359-372.

20. Biscayart C, Carrega MEP, Sagradini S, et al. Yellow fever vaccineassociated adverse events following extensive immunization in Argentina. Vaccine. 2014;32(11):1266-1272.

21. DeSilva M, Sharma A, Staples E, Arndt B, Shieh W-J, Shames J. Fatal yellow fever vaccine-associated viscerotropic disease - Oregon, September 2014. MMWR Morb Mortal Wkly Rep. 2015;64(10): 279-281.

22. Leung WS, Chan MC, Chik SH, Tsang TY. First case of yellow fever vaccine-associated viscerotropic disease (YEL-AVD) in Hong Kong. J Travel Med. 2016;23(4):taw020.

23. Isenman $\mathrm{H}$, Burns $\mathrm{A}$. A case of yellow-fever associated disease. $N Z$ Med J. 2012;125:92-95.

24. Fournier J-P, Bernardin G, Laffont C, et al. Vaccination anti amarile compliquée d'une primo infection grave par le virus de l'immunodeficience humaine (VIH 1): à propos d'une observation [Yellow fever vaccination complicated by a serious primary infection with HIV in connection with an observation]. Rétrovirus la Revue du Sida. 1989;2(4): $154-156$.

25. A Joint Statement of the US Public Health Service, North Carolina State Board of Health, Forsyth County Health Department and Bowman Gray School of Medicine. Fatal viral encephalitis following 17D yellow fever vaccine inoculation. Report of a case in a 3-year-old child. JAMA. 1966;198(6):671-672.

26. Bae $\mathrm{H}-\mathrm{G}$, Domingo $\mathrm{C}$, Tenorio A, et al. Immune response during adverse events after 17D-derived yellow fever vaccination in Europe. $J$ Infect Dis. 2008;197(11):1577-1584.
27. Pulendran B, Miller J, Querec TD, et al. Case of yellow fever vaccineassociated viscerotropic disease with prolonged viremia, robust adaptive immune responses, and polymorphisms in CCR5 and RANTES. J Infect Dis. 2008;198(4):500-507.

28. Muñoz J, Vilella A, Domingo C, et al. Yellow fever-associated viscerotropic disease in Barcelona, Spain. J Travel Med. 2008;15(3):202-205.

29. Struchiner CJ, Luz PM, Dourado I, et al. Risk of fatal adverse events associated with 17DD yellow fever vaccine. Epidemiol Infect. 2004; 132(5):939-946.

30. Gerasimon G, Lowry K. Rare case of fatal yellow fever vaccineassociated viscerotropic disease. South Med J. 2005;98(6):653-656.

31. Douce RW, Freire D, Tello B, Vasquez GA. Case report: a case of yellow fever vaccine-associated viscerotropic disease in Ecuador. Am J Trop Med Hyg. 2010;82(4):740-742.

32. Kennedy CC, Mullon J. Yellow fever vaccine associated viscerotropic disease in a young woman: a rare complication of a common vaccine. Crit Care Med. 2007;35(12 suppl):A286.

33. Vasconcelos PFC, Luna EJ, Galler R, et al; Brazilian Yellow Fever Vaccine Evaluation Group. Serious adverse events associated with yellow fever 17DD vaccine in Brazil: a report of two cases. Lancet. 2001;358(9276):91-97.

34. de Filippis AMB, Nogueira RMR, Jabor AV, et al. Isolation and characterization of wild type yellow fever virus in cases temporally associated with $17 \mathrm{DD}$ vaccination during an outbreak of yellow fever in Brazil. Vaccine. 2004;22(9-10):1073-1078.

35. Levy S, Mullane K, Miller M, et al. Adverse events associated with 17D-derived yellow fever vaccination - United States, 2001-2002. MMWR Morb Mortal Wkly Rep. 2002;51(44):989-993.

36. Belsher JL, Gay P, Brinton M, et al. Fatal multiorgan failure due to yellow fever vaccine-associated viscerotropic disease. Vaccine. 2007; 25(50):8480-8485.

37. Chan RC, Penney DJ, Little D, Carter IW, Roberts JA, Rawlinson WD. Hepatitis and death following vaccination with 17D-204 yellow fever vaccine. Lancet. 2001;358(9276):121-122.

38. Martin M, Tsai TF, Cropp B, et al. Fever and multisystem organ failure associated with 17D-204 yellow fever vaccination: a report of four cases. Lancet. 2001;358(9276):98-104.

39. de Mello Vieira J, Sinari V, Vasconcelos Dias FV. Um caso de hepatite letal após vacinação anti-amarílica [A case of fatal hepatitis due to yellow fever vaccine]. J Soc Cienc Med Lisb. 1965;129:51-72. Portuguese.

40. Zhou Q. Adverse effects of attenuated yellow fever vaccine with multiple organ injury - a case report. Zhong Hua Yi Xue Za Zhi. 2005;85(13):936.

41. Monath TP, Cetron MS, Teuwen DE. Yellow fever vaccine. In: Plotkin SA, Orenstein WA, Offit PA, editors. Vaccines. 5th ed. (Chap. 36). Philadelphia: Saunders/Elsevier; 2008:959-1056.

42. Monath TP. Short report: suspected yellow fever vaccine-associated viscerotropic adverse events (1973 and 1978), United States. Am J Trop Med Hyg. 2010;82(5):919-921.

43. Vellozzi C, Mitchell T, Miller E; Yellow Fever Vaccine Safety Working Group. Yellow fever vaccine-associated viscerotropic disease (YEL-AVD) and corticosteriod therapy: eleven United States cases, 1996-2004. Am J Trop Med Hyg. 2006;75(2):333-336.

44. Engel AR, Vasconcelos PFC, McArthur MA, Barrett ADT. Characterization of a viscerotropic yellow fever variant from a patient in Brazil. Vaccine. 2006;24:2803-2809.

45. O'Conghaile SO, Alsharbaty MJ, McDermott SR, Conlon PJ, Royston MD, Dwyer RC. Fulminant hepatitis and multisystem organ failure following yellow fever vaccination: description of a fatal case. Anaesth Intensive Care. 2014;42(3):423-424.

46. Kitchener S. Viscerotropic and neurotropic disease following vaccination with the 17D yellow fever vaccine, ARILVAX. Vaccine. 2004; 22(17-18):2103-2105.

47. Adhiyaman V, Oke A, Cefal C. Effects of yellow fever vaccination. Lancet. 2001;358:1907-1908.

48. Appenzeller S, Faria AV, Zanardi VA, Fernandes SR, Costallat LTL, Cendes F. Vascular involvement of the central nervous system and systemic diseases: etiologies and MRI findings. Rheumatol Int. 2008; 28(12):1129-1137. 
49. Rowland M, Plackett TP, Smith R. Yellow fever vaccine-associated viscerotropic disease. Mil Med. 2012;177(4):467-469.

50. Troillet N, Laurencet F. Letter to the editor. Lancet. 2001;358:1908-1909.

51. Turpo G, Ticona M, Uchuya J, Whittembury A, Seligman SJ. Third case of fatal yellow fever vaccine-associated viscerotropic disease in a young Peruvian woman. Am J Trop Med Hyg. 2010;87(5 suppl 1):383. [Conference of the Annual Meeting of the Am Soc Trop Med Hyg, Atlanta, November 2012, Conf Pub 87(5 Suppl 1):383].

52. Van Langenberg ER. Acute necrosis of the liver. An unusual case Lancet. 1944;243(6286):244-245.

53. Martins RDM, Maia MDLD, Santos EMD, et al. Yellow fever vaccine post-marketing surveillance in Brazil. Procedia Vaccinol. 2010;2(2): $178-183$

54. Ministério do Saúde, Brasil. Boletim de Atualização - Dezembro/2009 [webpage on the Internet]. Emergências em Saúde Pública de Importância Nacional (ESPIN) de Febre Amarela Silvestre em São Paulo e no Rio Grande do Sul e a Situação Epidemiólogica Atual no Brasil (2008/2009). Available from: http://portal.saude.gov.br. Accessed July 8, 2013.

55. Ministério do Saúde, Secretaria de Vigilancia em Saúde, Brasil [webpage on the Internet]. Oficina de Trabalho. Subsídios para Discussão e Redefinição da Estratégia de Vacinação Contra Febre Amarela No Brasil; 2009:22. Available from: http://portal.saude.gov.br. Accessed July 8, 2013.

56. Ministério do Saúde, Fundação Nacional de Saúde, Brasil [webpage on the Internet]. Eventos Adversos sérios Associados com a vacina 17D contra Febra Amarela; 2009:23. Available from: http://portal.saude. gov.br. Accessed July 8, 2013.

57. Romano AP, Costa ZG, Ramos DG, et al. Yellow fever outbreaks in unvaccinated populations, Brazil, 2008-2009. PLoS Negl Trop Dis. 2014;8(3):e2740.

58. Lawrence G, Menzies R, Burgess M, et al. Surveillance of adverse events following immunisation: Australia, 2000-2002. Commun Dis Intell. 2003;27(3):307-323.

59. Lawrence GL, Burgess MA, Kass RB. Age-related risk of adverse events following yellow fever vaccination in Australia. Commun Dis Intell. 2004;28(2):244-248.

60. Khromava AY, Eidex RB, Weld LH, et al; Yellow Fever Vaccine Safety Working Group. Yellow fever vaccine: an updated assessment of advanced age as a risk factor for serious adverse events. Vaccine. 2005; 23(25):3256-3263.
61. Lindsey NP, Schroeder BA, Miller ER, et al. Adverse event reports following yellow fever vaccination. Vaccine. 2008;26(48):6077-6082.

62. Nordin J, Parker ED, Vazquez-Benitez G, et al. Safety of the yellow fever vaccine: a retrospective study. J Travel Med. 2013;20(6):368-373.

63. van de Pol EM, Gisolf EH, Richter C. A case suspected for yellow fever vaccine-associated viscerotropic disease in the Netherlands. J Travel Med. 2014;21(6):421-424.

64. WHO [webpage on the Internet]. International travel and health. Yellow Fever. Geneva: World Health Organization. Available from: http:// www.who.int/ith/vaccines/yf/en/. Accessed May 24, 2016.

65. CDC [webpage on the Internet]. ACIP Yellow Fever Vaccine Recommendations. Available from: www.cdc.gov/vaccines/hcp/acip-recs/ vacc-specific/yf.html. Accessed May 24, 2016.

66. Monath TP, Cetron MS, McCarthy K, et al. Yellow fever 17D vaccine safety and immunogenicity in the elderly. Hum Vaccine. 2005;1(5): 207-214.

67. Schumacher Z, Bourquin C, Heininger U. Surveillance for adverse events following immunization (AEFI) in Switzerland-1991-2001. Vaccine. 2010;28(24):4059-4064.

68. Martin M, Weld LH, Tsai TF, et al. Advanced age a risk factor for illness temporally associated with yellow fever vaccination. Emerg Infect Dis. 2001;7(6):945-951.

69. Thomas RE, Lorenzetti DL, Spragins W. Mortality and morbidity among military personnel and civilians during the 1930s and World War II from transmission of hepatitis during yellow fever vaccination: systematic review. Am J Pub Health. 2013;103(3):e16-e29.

70. Monath TP, Gershman M, Staples JE, Barrett ADT. Yellow fever vaccine. In: Plotkin SA, Orenstein WA, Offitt PA, editors. Vaccines. 6th ed. (Chap. 38). Edinburgh: Elsevier/Saunders; 2013:870-968.

71. Seligman SJ. Yellow fever virus vaccine-associated deaths in young women. Emerg Infect Dis. 2011;17(10):1891-1893.

72. Miyaji KT, Luiz AM, Lara AN, et al. Active assessment of adverse events following yellow fever vaccination of persons aged 60 years or more. Hum Vaccin Immunother. 2013;9(2):277-282.

\section{Publish your work in this journal}

Drug Design, Development and Therapy is an international, peerreviewed open-access journal that spans the spectrum of drug design and development through to clinical applications. Clinical outcomes, patient safety, and programs for the development and effective, safe, and sustained use of medicines are the features of the journal, which

\section{Dovepress}

has also been accepted for indexing on PubMed Central. The manuscript management system is completely online and includes a very quick and fair peer-review system, which is all easy to use. Visit http://www.dovepress.com/testimonials.php to read real quotes from published authors. 